Conclusion Although attempted suicide patients should be referred for psychiatric assessment, many of them were not. It is important to strengthen the chain of care as well as to educate health providers and family members to prevent repeated suicide attempts.

\section{SP3-31 DETERMINANT FACTORS CONTRIBUTION TO THE DEATH OF INDONESIAN HAJJ PILGRIMS FOR THE AGES OF > 40 YEARS IN MECCA, SAUDI ARABIA}

doi:10.1136/jech.2011.1429760.31

N Kodim.* University of Indonesia, Jakarta, Indonesia

Introduction The mortality rate Indonesian Hajj Pilgrims is higher than Indonesian population mortality. The mortality rate of Indonesian hajj pilgrims fluctuated ranging from 2 to 3.8 per 1000 hajj. Methods and Materials This research conducted to the 149537 ordinary hajj pilgrims. Design of the study was cross-sectional ecological studies. Analysis was done using multilevel logistic regression.

Results Factors that contribute to mortality of Indonesian hajj pilgrims are age, sex, educational level, length of stay and preexisting diseases. The factors with the highest contributions to mortality were age $60-69$ years $(36.4 \%)$, age $>79$ years $(30.0 \%)$. male $(27.6 \%)$ and low education $(29.0 \%)$. Pre-existing disease contributed $<6 \%$ to the death rate. Adjusted real per capita expenditure, no access to health facilities adult literacy, populations with health problems and populations self medicating contributed to mortality of Indonesian hajj pilgrims after controlling for other variables.

Conclusions It appears safer for Moslems to go to Mecca before age 50 years. We would suggest paying increased attention to the Hajj pilgrims $>50$ years old, males, those that are thin, those who have lung diseases, metabolic problems or cardio-cerebrovascular and those who flight in the second turn. Further research is needed about the cause of death of Hajj pilgrims in order to assess the effects of environment conditions in Saudi Arabia on Indonesian Hajj pilgrims.

\section{SP3-32 NUTRITIONAL CORRELATES OF EXCESS WEIGHT AMONG ADOLESCENTS}

doi:10.1136/jech.2011.1429760.32

${ }^{1,2} \mathrm{Z}$ Afifi, ${ }^{*} \mathrm{H}$ Hassan, ${ }^{2} \mathrm{O}$ El-Mahgoub, ${ }^{3,4} \mathrm{~A}$ El-Sayed. ${ }^{1}$ College of Medicine, King Faisal University, Al Ahsa, Eastern province, Saudi Arabia; ${ }^{2}$ Faculty of Medicine, Cairo University, Cairo, Egypt; ${ }^{3}$ National Nutrition Institute, $\mathrm{MOH}$, Cairo, Egypt; ${ }^{4} \mathrm{MOH}, \mathrm{Al}$ Kasim, Saudi Arabia

Introduction This study was carried to study the nutritional correlates of excess weight among adolescent scholars.

Methods Two-phase study, a case finding survey followed by case control study. The survey was carried out in 4 schools in Cairo. It included 1551 students. Weight and height were measured. We classified them according to the WHO BMI cut-offs into excess weight (EWG) and normal weight (NWG) groups. Two stratified random samples, 151 each were selected from the two groups. We enquired about the nutritional knowledge, attitudes, self efficacy and dietary practices (24-h recall and Semi-quantitative-food frequency) in the two groups. The schools' nutrition service was assessed.

Results Overall prevalence of excess weight was 30.2\% (obesity $11.6 \%$ and overweight $18.6 \%$ ). The rate was slightly higher in females than in males ( $33.3 \%$ vs $27.2 \%$ respectively). EWG had lower mean scores of nutritional knowledge and sound dietary beliefs. Lower percentage of EWG knew about the causes of obesity, were satisfied with their current weight or had self efficacy $(p=0.000)$. One third tried to decrease weight previously and recently. Higher percentage EWG consumed $>100 \%$ RDA of protein and total energy; $>300 \mathrm{mg}$ cholesterol $(p=0.000)$. They consumed all food groups more frequently except fruits. Higher percentage had lots of snacks between meals and when bothered $(p=0.000$ and 0.02). School nutrition service was deficient and favoured the provision of high energy foods.

Conclusion There is a need to improve the knowledge, attitudes and dietary practices in this age group and to improve the nutrition service at school.

\section{SP3-33 MANAGEMENT AND PREVENTION OF DIABETES USING COMMUNITY- AND ICT-BASED PROGRAM IN JAPANESE RURAL COMMUNITIES}

doi:10.1136/jech.2011.142976o.33

${ }^{1} \mathrm{~K}$ Shiwaku, ${ }^{1,2} \mathrm{~T}$ Hamano, ${ }^{1} \mathrm{M}$ Iwamoto, ${ }^{1} \mathrm{M}$ Yamasaki, ${ }^{1} \mathrm{M}$ Takeda. ${ }^{1}$ Shimane University School of Medicine, Izumo, Japan; ${ }^{2}$ Shimane University, Matsue, Japan

In recent years, there has been rapid growth in non-communicable disease in developing and developed countries. Diabetes has been identified as a healthcare priority by the Japanese government and WHO. The growth in type 2 diabetes (diabetes) is due to increases in the number of people with diabetes associated with increased longevity and lifestyle changes. Approximately $13.5 \%$ of the Japanese population now has either diabetes or impaired glucose tolerance. This high prevalence of diabetes is associated with a significant economic burden, with diabetes accounting for up to $6 \%$ of the total healthcare budget. Living a healthy lifestyle and weight control will go a long way in preventing the risk of diabetes and other related complications. The Shimane Study, which was undertaken in collaboration with rural communities, revealed prevalence of diabetes increased with urbanisation. Residents in the rural communities had few intakes of lipid and protein, and higher exercise by farming, compared to those in local city. We recruited 188 volunteers with prediabetes for the multi-component 3-month health promotion program, covering nutrition, physical activity and supportive group therapy health promotion program from participates of cohort study. All the participants completed the program from December 2009 by supported the Ministry of Economy, Trade and Industry. Improvement of glucose tolerance was remarkable to change their lifestyle in the higher group with HbA1c. We are developing a new community- and ICT-based program from 2010 by supported the Ministry of Internal Affairs and Communications.

\section{SP3-34 THE OVERVIEW AND PROSPECTS OF "JAPAN ECO \& CHILD STUDY" IN FUKUSHIMA}

doi:10.1136/jech.2011.1429760.34

S Yasumura, ${ }^{*}$ K Hashimoto, M Hoshoya, K Fujimori, Y Wakagi. Fukushima Medical University, School of Medicine, Fukushima, Japan

Introduction The Japanese Ministry of the Environment has begun a birth cohort study, Japan Eco \& Child Study, to clarify the influence environmental risks on children (http://www.env.go.jp/chemi/ceh/ index.html). This study will be conducted on 100000 pregnant mothers and their children from across Japan from 2011. Twenty-six areas across Japan offered to participate in this project, and 15 sites, including Fukushima Medical University, were chosen. The purpose of this birth cohort study is to elucidate an important hypothesis: that environmental factors, including the exposure of children from the fetal period to early childhood to chemical compounds, affects pregnancy/reproduction, the incidence of congenital anomalies, mental development, immunology/allergy, and metabolism/endocrine systems. If environmental agents affecting the growth/ 